\title{
Systematics of Juniperus from eastern Asia based on Random Amplified Polymorphic DNAs (RAPDs)
}

\author{
Robert P. Adams a,*, Chang-Fu Hsieh ${ }^{\text {b }}$, Jin Murata ${ }^{\mathrm{c}}$, \\ Ram Naresh Pandey ${ }^{\mathrm{d}}$ \\ a Plant Biotechnology Center, Baylor University, Box 669, Gruver, TX 79040, USA \\ ${ }^{\mathrm{b}}$ Department of Botany, National Taiwan University, Taipei 106, Taiwan \\ c Botanic Gardens, Koishikawa, Graduate School of Science, University of Tokyo, 3-7-1 Hakusan, \\ Bunkyo-ku, Tokyo 112-0001, Japan \\ ${ }^{\mathrm{d}}$ RECAST, Tribhuvan University, Kirtipur, Kathmandu, Nepal
}

Received 12 December 2000; accepted 5 March 2001

\begin{abstract}
DNA was examined by RAPD banding for Junipers chinensis, J.c. var. sargentii, J.c. var. tsukusiensis, J. communis, J.c. var. nipponica, J.c. var. saxatilis, J. conferta, J. formosana, J. procumbens, J. rigida, J. taxifolia and J.t. var. lutchuensis. The DNA data readily separated junipers of section Sabina from section Juniperus. J.c. var. tsukusiensis from Taiwan was found to be sufficiently different from J.c. var. tsukusiensis (Yakushima) to warrant the recognition of a new variety: J. chinensis var. taiwanensis R.P. Adams and C-F. Hsieh nov var. Juniperus formosana from mainland China was found to be different from J. formosana from Taiwan and a new variety is recognized: J. formosana var. mairei (Lemee and Lev.) R.P. Adams and C-F. Hsieh comb. nov. Juniperus communis var. nipponica was found to be very distinct from $J$. communis and this supports its recognition as a variety. The recognition of $J$. conferta as a variety of $J$. rigida [J. rigida var. conferta (Parl.) Patschke] is supported by the data. The data also supports the recognition of J. lutchuensis Koidz. [=J. taxifolia var. lutchuensis (Koldz.) Satake] and J. morrisonicola Hayata [=J. squamata var. morrisonicola (Hayata) H.L. Li and H. Keng] at the specific levels. (C) 2002 Elsevier Science Ltd. All rights reserved.
\end{abstract}

* Corresponding author. Tel.: +1-806-733-5558; fax: +1-806-733-5605.

E-mail address: rpadams@juno.com (R.P. Adams). 
Keywords: Juniperus; Cupressaceae; RAPDs; DNA polymorphisms; Systematics; Taxonomy; Japan; Taiwan; China

\section{Introduction}

The genus Juniperus consists of approximately seventy species, all of which grow in the northern hemisphere, although, J. procera Hochst. ex Endl. also grows southward along the rift mountains in east Africa into the southern hemisphere (Adams and Demeke, 1993). The genus is divided into three sections: Caryocedrus (one species, J. drupacea Labill.); Juniperus (= Oxycedrus, 14 species, Adams, 2000a) and Sabina (the remaining, approx. 55 species, Adams, 1999, 2000b,c,d, 2001).

Both sections Juniperus and Sabina are represented in Japan and Taiwan. The taxonomy of these junipers has been in flux for some time. This can be seen from Table 1. Several areas of disagreement are seen. For example, J. procumbens is also recognized as J. chinensis var. procumbens; J. communis var. nipponica is recognized as $J$. rigida; $J$. conferta is recognized as $J$. rigida var. conferta; and J. taxifolia var. lutchuensis not recognized by Farjon (1998).

In addition, the nomenclature in Taiwan has changed from the Flora of Taiwan

Table 1

Comparison of the taxonomic treatments of Juniperus species native to Japan and Taiwan analyzed in this study. N.A.=not analyzed

\begin{tabular}{|c|c|c|c|}
\hline $\begin{array}{l}\text { In Japan: } \\
\text { Kitamura and Murata (1979) }\end{array}$ & Ohwi (1965) & Farjon (1998) & DNA data \\
\hline J. chinensis & J. chinensis & J. chinensis & J. chinensis \\
\hline J.c. var. sargentii & J.c. var. sargentii & J.c. var. sargentii & J.c. var. sargentii \\
\hline J.c. var. procumbens & J.c. var. procumbens & J. procumbens & J. procumbens \\
\hline J.c. var. sargentii & J.c. var. sargentii & J.c. var. tsukusiensis & J.c. var. tsukusiensis \\
\hline \multicolumn{4}{|l|}{ J. communis: } \\
\hline J.c. var. hondoensis & J.c. var. hondoensis & - & N.A. \\
\hline J.c. var. nipponica & J.c. var. nipponica & $=J$. rigida & J.c. var. nipponica \\
\hline J.c. var. saxatilis & J.c. var. montana & - & aff. J.c. var. saxatilis? \\
\hline J. rigida & $J$. rigida & J. rigida & J. rigida \\
\hline J.r. var. conferta & J. conferta & J.r. subsp. conferta & J.r. var. conferta \\
\hline J. taxifolia & - & J. taxifolia & J. taxifolia \\
\hline J.t. var. lutchuensis & - & J. taxifolia & J. lutchuensis \\
\hline \multicolumn{4}{|l|}{ In Taiwan: } \\
\hline Flora of Taiwan (1994) & Li and Keng, 1954 & Farjon (1998) & DNA data \\
\hline J. chinensis. var. tsukusiensis & J.c. var. tsukusiensis & J.c. var. tsukusiensis & J.c. var. taiwanensis \\
\hline J. formosana & J. formosana & $J$. formosana & J. formosana \\
\hline J. formosana var. concolor & $J . f$. var. concolor & J. formosana & Extinct? \\
\hline J. squamata & $\begin{array}{l}\text { J. s. var. } \\
\text { morrisonicola }\end{array}$ & J. squamata & J. morrisonicola \\
\hline
\end{tabular}


(1975) to 1994. In 1975, four Juniperus taxa were recognized: J.. var. tsukusiensis; J. formosana; J. formosana var. concolor and J. squamata var. morrisonicola, whereas in the 1994 Flora of Taiwan, J. squamata var. morrisonicola was recognized as merely $J$. squamata.

The purpose of this paper is to examine Juniperus species from eastern Asia (principally Japan and Taiwan) by the use of data from Random Amplified Polymorphic DNAs (RAPDs) to better understand the systematics of these junipers. We have also added to the analysis samples of J. formosana Hayata (China), J. communis (Sweden), and J. communis var. saxatilis (Switzerland and Mongolia) for comparisons.

\section{Materials and methods}

Specimens used in this study: J. chinensis, Adams 8536, 8537, Osezaki Point, Shizuoka Prefecture, Japan; J.c. var. sargentii Adams 8683, 8684 Matsumae-Jyoshi Park, Hokkaido, Japan (collected by Naotoshi Yohsida), Adams 8689, cultivated, Iwate Prefecture, Japan (collected by Naotoshi Yohsida); Adams 8580, Mt. Hayachine, Iwate Prefecture, Japan and Adams 8688, Mt. Kirigishi, Hokkaido, Japan (collected by Naotoshi Yohsida); J.c. var. tsukusiensis, Adams 9061, 9062, Mt. Chingshui, Taiwan, cult., Taiwan Forestry Institute, Taiwan; J.c. var. tsukusiensis, Adams 8805, 8806, Yakushima, Japan (by Jin Murata), J. conferta, Adams 8585, 8586, Tottori Sand Dunes, Japan (provided by Jin Murata); J. communis var. communis, Adams 7846, 7848, Stockholm, Sweden; J.communis var. nipponica, Adams 8579, Mt. Hayachine, Iwate Prefecture, Japan and Adams 8690, cultivated, Kidaka, Hokkaido (provided by Naotoshi Yohsida); J.c. var. saxatilis, Adams 7618, 7619, Switzerland; J.c. var. saxatilis, Adams 7589, 7590, Altai Mts., Mongolia, putative J.c. var. saxatilis; Adams 8685, 8686, 8687, cultivated, Teshio Experimental Forest of Hokkaido University, Hokkaido, Japan (provided by Naotoshi Yohsida); J. formosana, Adams 6772, 6774, Gansu, China; J. formosana, Adams 8781, Fujian, 400 m, China (by Zhen-Yu Li); J. formosana, Adams 9059-9060, Mt. Chingshui, Taiwan; J. formosana, Adams 9046, seedling, $30 \mathrm{~m}$, Chungte tunnel, Taiwan; J. formosana, Adams 9065-9066, 430 m, Lushui, Taiwan; J. formosana, Adams 9071-9072, 3230 m, Shihmenshan, Taiwan; J. procumbens (Seib. ex. Endl.) Miq., Adams 8398, Hillier Gardens, UK, Acc. \#76.2779, Adams 9150, Arnold Arboretum, Acc. \#1163-56; J. rigida, Adams 8544, 8545, Gifu Prefecture, Japan (provided by Jin Murata); J. taxifolia, Adams 8448, 8449, Bonin Islands, Japan (provided by Jin Murata), J. taxifolia var. lutchuensis, Adams 8541, 8542, Oshima Island, Japan. Voucher specimens are deposited at SRCG herbarium, Baylor University.

One gram (fresh weight) of the foliage was placed in $20 \mathrm{~g}$ of activated silica gel and transported to the lab, thence stored at $-20^{\circ} \mathrm{C}$ until the DNA was extracted. DNA was extracted from juniper leaves by the hot CTAB protocol (Doyle and Doyle, 1987) with $1 \%$ (w/v) PVP added to the extraction buffer. The RAPD analyses follow that of Adams and Demeke (1993). Ten-mer primers were purchased from the University of British Colombia $\left(5^{\prime}-3^{\prime}\right)$ : 116: TAC GAT GAC G; 134: AAC ACA CGA 
G; 153: GAG TCA CGA G; 204: TTC GGG CCG T; 212: GCT GCG TGA C; 218: CTC AGC CCA G; 239: CTG AAG CGG A; 249: GCA TCT ACC G; 250: CGA CAG TCC C; 265: CAG CTG TTC A; 327: ATA CGG CGT C; 338: CTG TGG CGG T; 346: TAG GCG AAC G; 347 TTG CTT GGC G; 375: CCG GAC ACG A; 391: GCG AAC CTC G; 413: GAG GCG GCG A; 431: CTG CGG GTC A.

PCR was performed in a volume of $15 \mu l$ containing $50 \mathrm{mM}$ Tris- $\mathrm{HCl}(\mathrm{pH} 9)$, $2.0 \mathrm{mM} \mathrm{MgCl}, 0.01 \%$ gelatin and $0.1 \%$ Triton X-100, $0.2 \mathrm{mM}$ of each dNTPs, 0.36 $\mu \mathrm{M}$ primers, $0.3 \mathrm{ng}$ genomic DNA, $15 \mathrm{ng}$ BSA and 0.6 unit of Taq DNA polymerase (Promega). A control PCR tube containing all components, but no genomic DNA, was run with each primer to check for contamination. DNA amplification was performed in an MJ Programmable Thermal Cycler (MJ Research, Inc.). The thermal cycle was: $94^{\circ} \mathrm{C}(1.5 \mathrm{~min})$ for initial strand separation, then 40 cycles of $38^{\circ} \mathrm{C}(2 \mathrm{~min})$, $72^{\circ} \mathrm{C}(2 \mathrm{~min}), 91^{\circ} \mathrm{C}(1 \mathrm{~min})$. Two additional steps were used: $38^{\circ} \mathrm{C}(2 \mathrm{~min})$ and $72^{\circ} \mathrm{C}(5 \mathrm{~min})$ for final extension.

Bands that occurred once or did not show fidelity within the two replicated samples of each taxon were eliminated. It should be noted that these bands contain very useful information for the study of genetic variance and individual variation, but are merely "noise" in the present taxonomic study. Bands were scored in four classes: very bright $(=6)$; medium bright $(=5)$, faint $(=4)$ and absent $(=0)$. See Adams and Demeke (1993) for details on electrophoresis and RAPD band scoring.

Similarity measures were computed using absolute character state differences (Manhattan metric), divided by the maximum observed value for that character over all taxa (=Gower metric, Gower, 1971; Adams, 1975a,b). Principal coordinate analysis (PCO) of the similarity matrix follows Gower (1966).

\section{Results and discussion}

\subsection{Section Sabina}

Preliminary analysis (Adams, in preparation) of the leaf oils revealed the plants collected as J.c. var. sargentii were of two oil types: high bornyl acetate, low sabinyl acetate $(8683,8684,8689)$ and low bornyl acetate, high sabinyl acetate $(8580,8688)$. So all of these specimens were used for the DNA analysis to examine the RAPDs of these chemical polymorphisms.

Fig. 1 shows the minimum spanning network for the Juniperus in section Sabina analyzed in this study. The major trend is the separation of J. chinensis taxa from $J$. procumbens, Japan, J. morrisonicola Hayata, Taiwan, and J. squamata Buch.Ham. ex. D. Don, Gansu, China. Kitamura and Murata (1979) and Ohwi (1965) treated J. procumbens as a variety of J. chinensis, but this study supports Farjon (1998) in maintaining $J$. procumbens as a distinct species. Adams (2000c) showed that J. morrisonicola and J. squamata are distinct at the specific level in both RAPDs and leaf essential oils, and this analysis re-affirms their distinctness.

It appears that five taxa are present within the J. chinensis complex (Fig. 1): J.c. var. chinensis, J.c. var. tsukusiensis (Yakushima), J.c. var. tsukusiensis (Taiwan), 


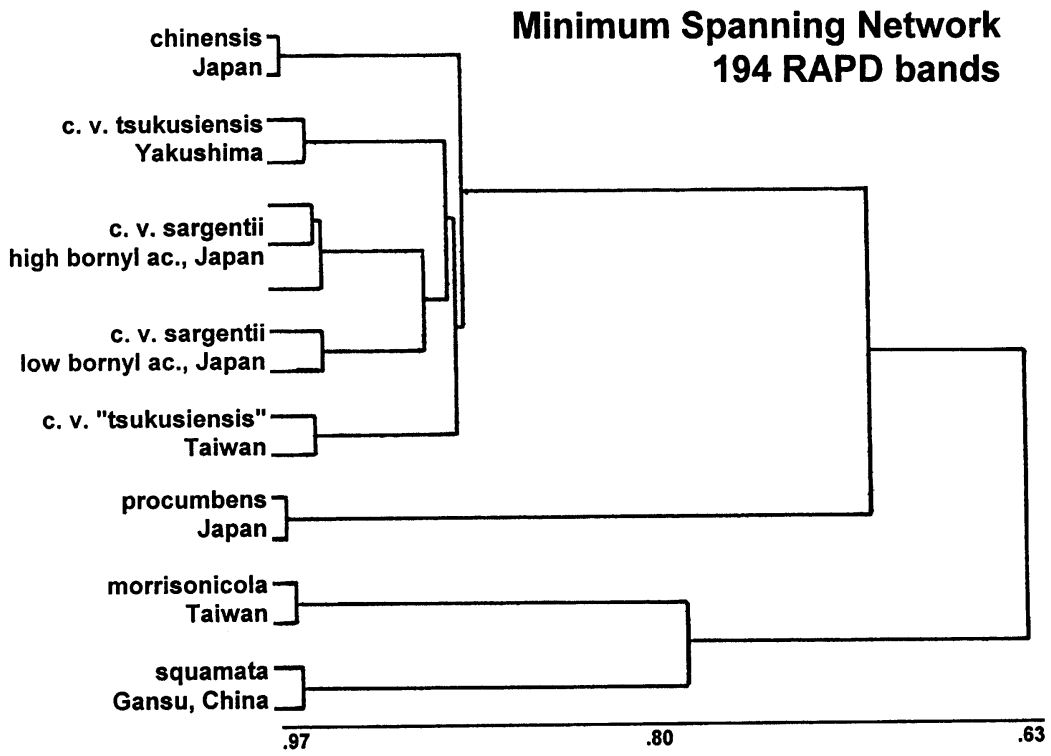

Fig. 1. Minimum spanning network based on 194 RAPD bands for Juniperus section sabina. Notice the distinct nature of $J$. squamata, J. morrisonicola and $J$. procumbens.

J.c. var. sargentii (high bornyl acetate, low sabinyl acetate), and J.c. var. sargentii (high sabinyl acetate, low bornyl acetate).

In order to facilitate the examination of the J. chinensis taxa, both J. morrisonicola and J. squamata were removed from the data set. The similarities were re-calculated and principal coordinates analysis was performed on the similarity matrix involving the five J. chinensis groups (Fig. 2). PCO revealed the groups (Fig. 2) were about equally similar. A significant point is that J. chinensis var. tsukusiensis from Yakushima did not cluster with J.c. var. tsukusiensis from Taiwan (Figs. 1 and 2). The Taiwan population of J. chinensis var. tsukusiensis occurs near (but not on) the summit of Mt. Chingshui, Taiwan. It is very isolated and consists of an estimated few hundreds of individuals. In the PCO it appears somewhat removed from the other varieties of J. chinensis (Fig. 2). But its linkage to other varieties of J. chinensis is at a comparable level of similarity. Clearly, it is not the same as J.c. var. tsukusiensis from Yakushima (the type locality and only population). It seems consistent to recognize this genetic variation expressed as the population on Mt. Chingshui as a distinct variety: J.c. var. taiwanensis R.P. Adams and C-F. Hsieh, var. nov., TYPE: Mt. Chingshui, Taiwan, 2200 m, Sheng-you Lu 14498 (holotype at TAIF).

Frutices procumbentes, ramuli terminalibus ascendentibus. Foliae squamiformiae apicibus obtusis ca $1 \mathrm{~mm}$ longae et latae. Galbuli globosi 5-8 $\mathrm{mm}$ in diametro. Semina 3 erecta trigono-elliptica.

Prostrate shrubs, terminal branchlets ascending, leaves scale like, apices obtuse, about $1 \mathrm{~mm}$ long, $1 \mathrm{~mm}$ wide. Scale leaves appear as a string of beads. Female cones, about $5 \mathrm{~mm}$ in diameter. Seeds 3, erect, triangular-elliptical. 


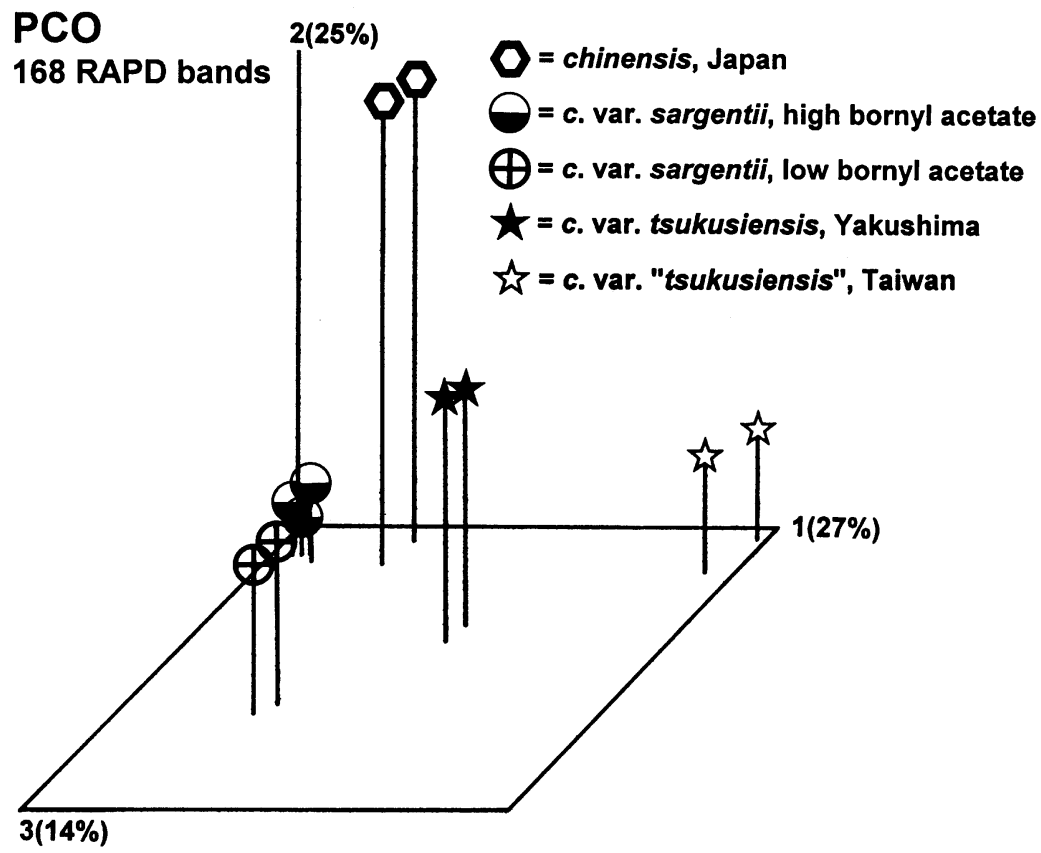

Fig. 2. PCO ordination of the J. chinensis taxa. Note the separation of J.c. var. tsukusiensis, Japan from J.c. var. "tsukusiensis", Taiwan. The two types of J.c. var. sargentii are: high bornyl acetate (half circles) and high sabinyl acetate (cross circles).

This variety differs from the typical variety by being a prostrate shrub and having scale leaves that are very short and wide (appearing as a string of beads) and with glands that are raised (as opposed to sunken in the typical variety). It differs form J.c. var. tsukusiensis in having scale leaves that are very short and wide and having the ultimate branchlets shorter $(1-1.5 \mathrm{~cm})$ than in J.c. var. tsukusiensis $(1.5-2 \mathrm{~cm})$.

J.c. var. taiwanensis is known from only one location: Mt. Chingshui. This area is a protected area, but due to the very small population, the taxon should be considered as threatened, but not endangered.

The three high bornyl acetate J.c. var. sargentii plants form a loose group that is distinct from the high sabinyl acetate J.c. var. sargentii plants (Figs. 1 and 2). Additional field work and sampling will be needed to understand these variations.

\subsection{Section Juniperus}

Analysis of Juniperus, sect. Juniperus is shown in Fig. 3. Four major groups are present: J. communis-conferta-rigida; J. formosana; J. lutchuensis; and J. taxifolia. Adams (2000a), using both leaf essential oils and RAPDs, found J. lutchuensis (=J. taxifolia var. lutchuensis) to be distinct from J. taxifolia and recognized J. lutchuensis as a separate species. This study reconfirms the previous work (Adams, 2000a).

Two sub-groups are apparent within the J. communis-conferta-rigida complex: 


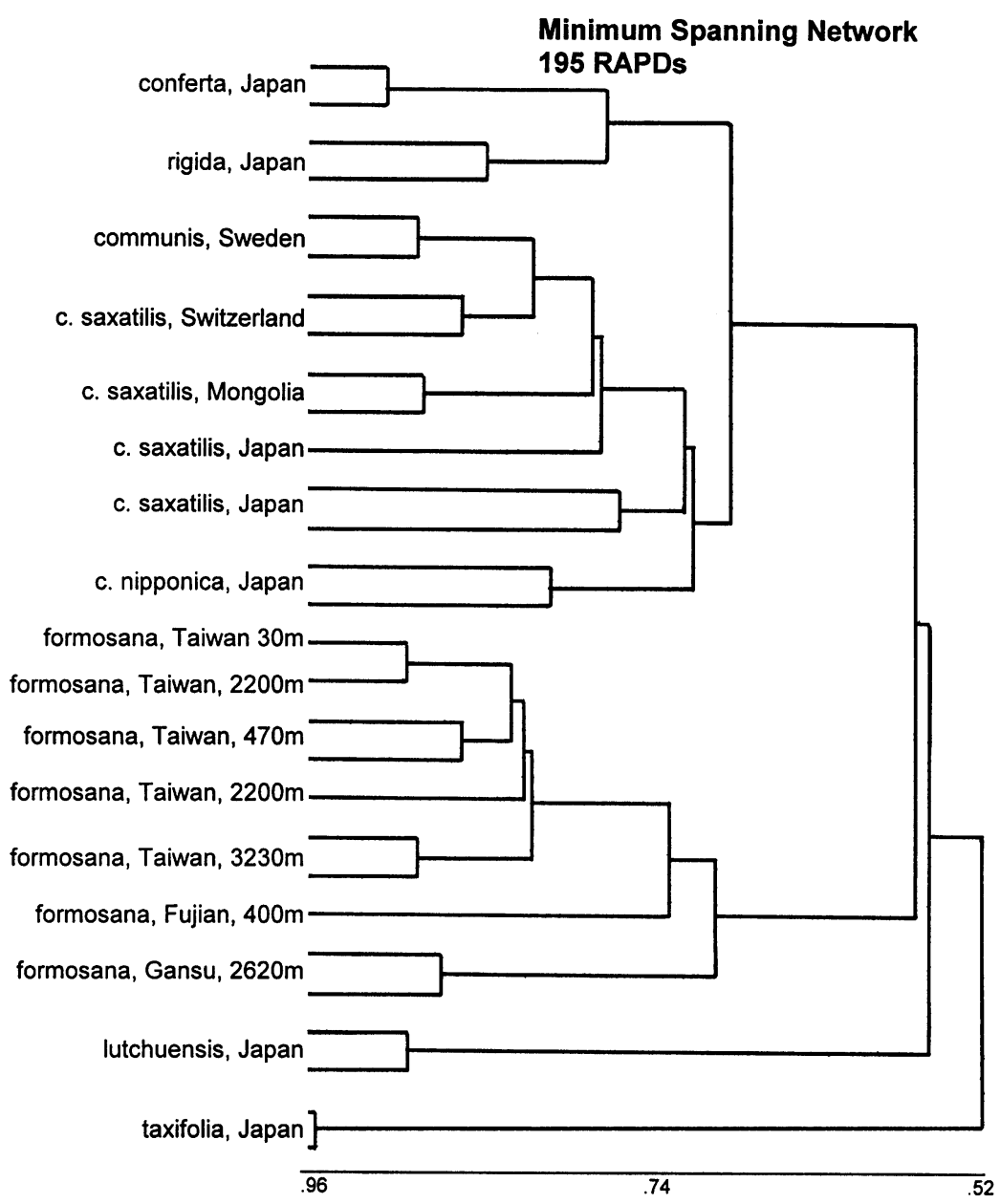

Fig. 3. Minimum spanning network based on 195 RAPD DNA bands Juniperus section Juniperus. See text for discussion.

J. communis-nipponica and J. conferta-rigida (Fig. 3). J. conferta has been treated as a species and as a subspecies of J. rigida (Table 1). Previously, Adams (2000a) found that the leaf essential oils and RAPDs supported the treatment of J. conferta as a variety, J. rigida var. conferta (Parl.) Patschke and this study reconfirms that decision.

The plants collected as J. communis var. nipponica barely cluster separately from J. communis (Fig. 3). The samples of putative J. communis var. saxatilis from Japan (Fig. 3) proved to be difficult to classify. The samples within the J. communisconferta-rigida complex were re-analyzed and a PCO was performed. This resulted in an ordination (Fig. 4) that may more clearly show these complex relationships. Note the J. conferta-rigida group and that $J$. c. var. nipponica is quite distinct (Fig. 


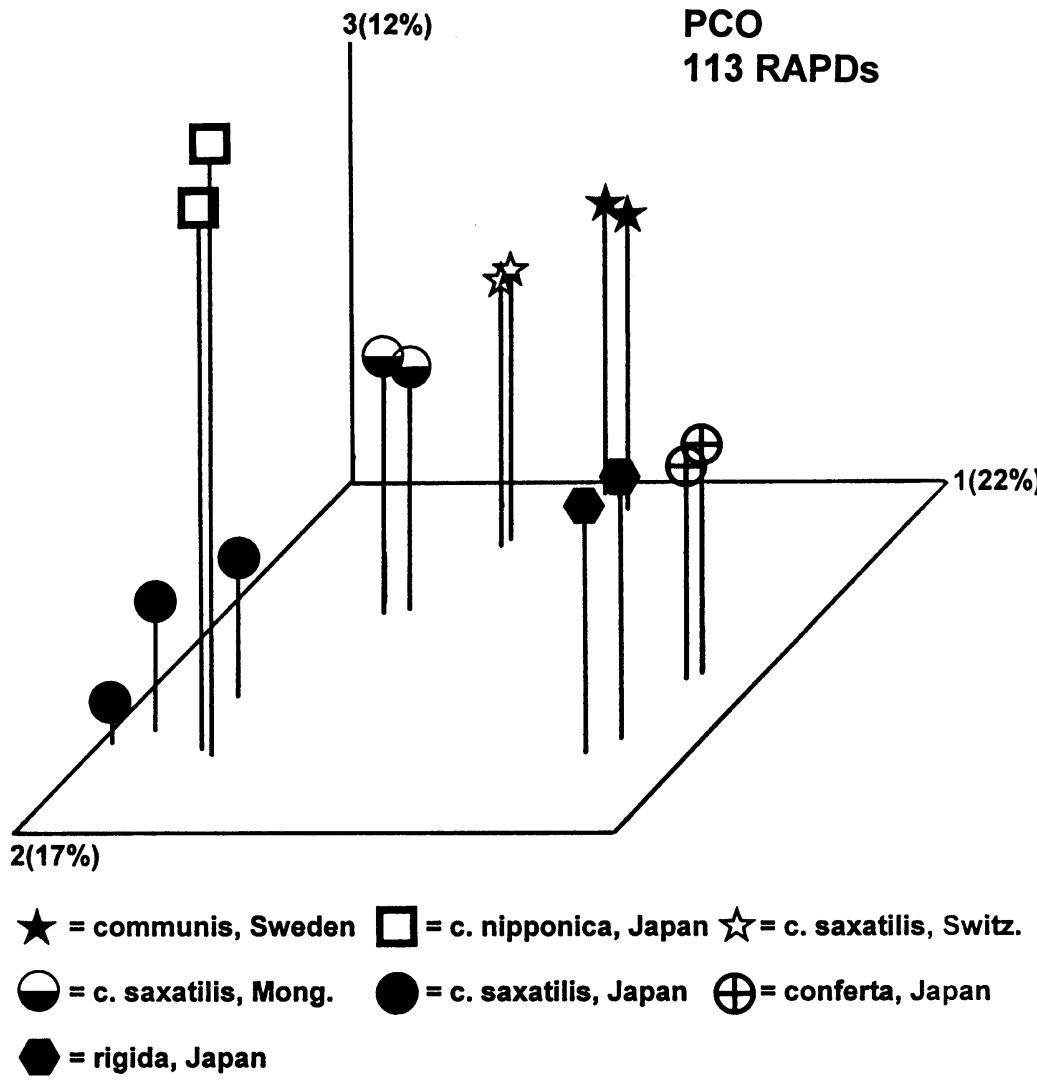

Fig. 4. Principal coordinate analysis (PCO) of the $J$. communis-conferta-rigida complex. Note the distinctness of J.c. var. nipponica and the sub-cluster of J. conferta-J. rigida.

4). The divergence and distinct nature of J.c. var. nipponica supports its continued varietal recognition.

It is interesting to note the gradient of J. communis and J.c. var. saxatilis in Fig. 4. Note that from upper right to lower left, one finds: J. communis, Sweden (solid stars); J.c. var. saxatilis, Switzerland (open stars); J.c. var. saxatilis, Mongolia (half circles); and J.c. var. saxatilis, Japan (solid circles). Adams (2000a) proposed that J.c. var. saxatilis from Mongolia be recognized as J. siberica Burgsd. From Fig. 4, the plants from Mongolia are about as distinct as J. communis var. saxatilis (Switzerland) is distinct from J. communis var. communis (Sweden). This would indicate that might be more appropriate to recognize the Mongolian plants as a distinct variety.

The loose clustering of the Japanese J.c. var. saxatilis plants (Fig. 3) indicates that additional studies are needed to resolve the status of these specimens. It may be that hybridization and introgression is responsible for the poorly defined clustering of J.c. var. saxatillis from Japan. 
The second large cluster (Fig. 3) is composed of J. formosana. All of the specimens from Taiwan form a cluster(Fig. 3) and the plants from mainland China appear quite differentiated. The $J$. formosana specimens were utilized to calculate a new similarity matrix which was factored by PCO. These results (Fig. 5), show all the J. formosana from Taiwan in the foreground (Fig. 5), then the Fujian specimen and the Gansu specimens in the background. The mainland populations are quite different from those on Taiwan (in fact as different as J. rigida is from J. communis (Fig. 3). The mainland $J$. formosana has been described as $J$. mairei Lemee and Lev. from Yunnan. Based on the present data, it appears that the mainland portion of J. formosana should be recognized at least at the variety level: Juniperus formosana var. mairei (Lemee and Lev.) R.P. Adams and C-F. Hsieh, stat nov.

BASIONYM: Juniperus mairei Lemee and Lev., Monde Pl. 2(16): 20 (1914). E.E. Maire, Jong-tohouan, Arnold Arboretum, bar code \#38339.

Finally, it should be mentioned that we searched the only known location of $J$. formosana var. concolor Hayata near the seashore (ca. $30 \mathrm{~m}$ ) and found only one seedling. This seedling shows high affinity to J. formosana from Mt. Chingshui $(2200 \mathrm{~m})$ (Fig. 3, solid star in Fig. 4). It appears that Mt. Chingshui is the likely source of the seed that produced that seedling. No plants of J. formosana var. con-

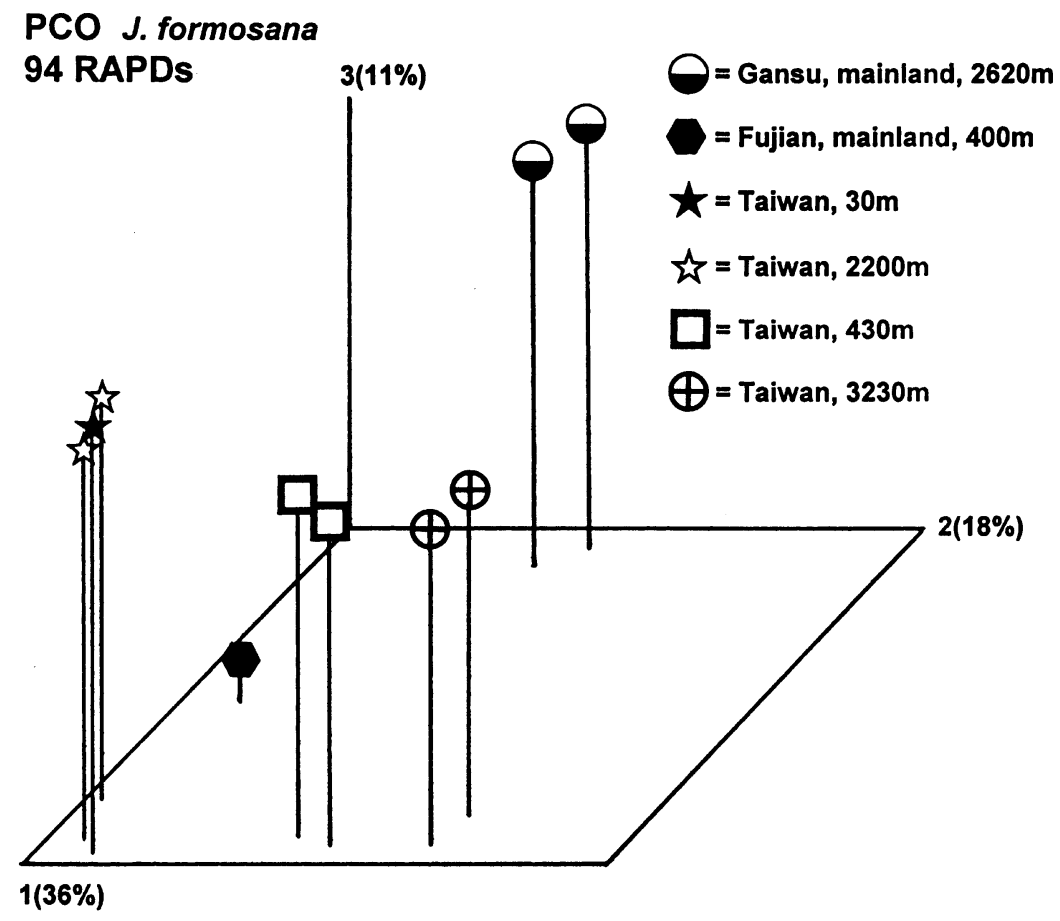

Fig. 5. PCO of the J. formosana samples. Notice the separation of the mainland samples (Gansu, Fujian) from the Taiwan samples. 
color were found and it is presumed that the plant used as the type specimen for var. concolor is now extinct.

In summary, we found the RAPD markers to be in good agreement with classical morphological taxonomy (Table 1). However, there are a couple of cases where nearly morphological identical taxa exhibited large differences in their DNA. These "cryptic" species challenge our traditional taxonomic framework. Hopefully, these additional data will provide with a more stable classification as well as encourage continued research on the near-Eastern Juniperus.

\section{Acknowledgements}

This research was supported in part with funds from Baylor University. Thanks to Naotoshi Yoshida for supplying Juniperus samples from Japan and Zhen-Yu Li for J. formosana from Fujian. Thanks to Paul Fryxell for assistance on the Latin description.

\section{References}

Adams, R.P., 1975a. Numerical-chemosystematic studies of infraspecific variation in Juniperus pinchotii. Sudw. Biochem. Syst. Ecol. 3, 71-74.

Adams, R.P., 1975b. Statistical character weighting and similarity stability. Brittonia 27, 305-316.

Adams, R.P., 1999. Systematics of multi-seeded eastern hemisphere Juniperus based on leaf essential oils and RAPD DNA fingerprinting. Biochem. Syst. Ecol. 27, 709-725.

Adams, R.P., 2000a. Systematics of Juniperus section Juniperus based on leaf essential oils and RAPD DNA fingerprinting. Biochem. Syst. Ecol. 28, 515-528.

Adams, R.P., 2000b. Systematics of smooth leaf margin Juniperus of the western hemisphere based on leaf essential oils and RAPD DNA fingerprinting. Biochem. Syst. Ecol. 28, 149-162.

Adams, R.P., 2000c. Systematics of the one seeded Juniperus of the eastern hemisphere based on leaf essential oils and random amplified polymorphic DNAs (RAPDs). Biochem. Syst. Ecol. 28, 529-543.

Adams, R.P., 2000d. The serrate leaf margined Juniperus (Section Sabina) of the western hemisphere: Systematics and evolution based on leaf essential oils and Random Amplified Polymorphic DNAs (RAPDs). Biochem. Syst. Ecol. 28, 975-989.

Adams, R.P., 2001. Geographic variation in leaf essential oils and RAPDs of J. polycarpos K. Koch in central Asia. Biochem. Syst. Ecol. (in press).

Adams, R.P., Demeke, T., 1993. Systematic relationships in Juniperus based on random amplified polymorphic DNAs (RAPDs). Taxon 42, 553-572.

Doyle, J.J., Doyle, J.L., 1987. A rapid DNA isolation procedure for small quantities of fresh leaf tissue. Phytochemical Bull. 19, 11-15.

Farjon, A., 1998. World Checklist and Bibliography of Conifers. Royal Botanic Gardens, Kew.

Flora of Taiwan, 1975. Li, H-L., Liu, T-S., Huang, T-C., Koyama, T., De Vol, C.E. (Eds.), Epoch, Taipei, Taiwan, pp. 538-544.

Flora of Taiwan, 1994. Huang, T.-C., Hsieh, C.-F., Keng, H., Hsieh W.-C., Tsai, J.-L. (Eds.), Editoral committee, Taipei, Taiwan, pp. 591-595.

Gower, J.C., 1966. Some distance properties of latent root and vector methods used in multivariate analysis. Biometrika 53, 326-338. 
Gower, J.C., 1971. A general coefficient of similarity and some of its properties. Biometrics 27, 857-874. Kitamura, S., Murata, G., 1979. Colored Illustrations of woody plants of Japan, vol. II. Hoikusha, Osaka. Li, H.L., Keng, H., 1954. Icones gymnospermum formosanarum, Taiwania 5, 25-83.

Ohwi, J., 1965. In: Meyer, F.G., Walker, E.H. (Eds.), Flora of Japan. Smithsonian Institute, Washington, DC. 